\title{
THE PALLADIOLIBRARY GEO-MODELS: AN OPEN 3D ARCHIVE TO MANAGE AND VISUALIZE INFORMATION-COMMUNICATION RESOURCES ABOUT PALLADIO
}

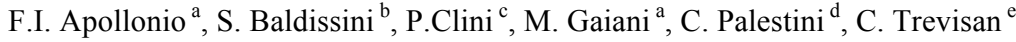 \\ ${ }^{a}$ Dipartimento di Architettura -Università di Bologna, Bologna, Italy - (fabrizio.apollonio, marco.gaiani)@unibo.it \\ ${ }^{\mathrm{b}}$ Centro Internazionale di Studi di Architettura Andrea Palladio di Vicenza, Vicenza, Italy - sbaldiss@gmail.com \\ ${ }^{\mathrm{c}}$ DICEA, Università Politecnica delle Marche, Ancona, Italy - p.clini@univpm.it \\ d Dipartimento di Architettura - Università degli Studi “G. d'Annunzio" di Chieti - Pescara, Italy - palestini@unich.it \\ ${ }^{\mathrm{e}}$ Università IUAV di Venezia, Venezia, Italy - trevisan@iuav.it
}

KEY WORDS: 3D digital libraries, Architectural heritage, georeferencing, virtual anastylosis, photogrammetry, spherical panorama, 3D modelling from drawings, real time rendering, geo-models.

\begin{abstract}
:
The paper describes objectives, methods, procedures and outcomes of the development of the digital archive of Palladio works and documentation: the PALLADIOLibrary of Centro Internazionale di Studi di Architettura Andrea Palladio di Vicenza (CISAAP). The core of the application consists of fifty-one reality-based 3D models usable and navigable within a system grounded on GoogleEarth. This information system, a collaboration of four universities bearers of specific skills returns a comprehensive, structured and coherent semantic interpretation of Palladian landscape through shapes realistically reconstructed from historical sources and surveys and treated for GE with Ambient Occlusion techniques, overcoming the traditional display mode.
\end{abstract}

\section{INTRODUCTION}

Since the middle 1990s the CISAAP has developed a specific line of research on how Information Technology can aid documentation and architectural displays, thanks to the resolute encouragement by the President of the Scientific Board, Howard Burns (Gaiani, 2008). After a successful trilogy of multimedia CD-ROM of the late nineties (Beltramini, 2002), Digital Palladio project was activated between 2002-2004 with the aim to digitalize and to reorganize into a unique database of Palladio's works documentation (photographs, drawings, engravings, sculptural reliefs, archived documents) (Beltramini \& Gaiani, 2003). Recently CISAAP launched the PALLADIOLibrary project (Gaiani \& Beltramini, 2012), a new system that, using new information technologies now available to all (real-time rendering of 3D models, Web 3.0, geospatial systems) aims to unify and display all the key materials for an understanding and appreciation of Andrea Palladio's work. It is about his drawings, the largest existing photo library devoted to Palladio (over 5,000 photos), approximately 1,200 survey drawings, Palladio's writings (nearly 8,000 pages) as well as a set of multimedia and virtual reconstructions that allow both specialists and the general public to learn about Andrea Palladio's world: 54 constructions spanning houses, public buildings, palaces, churches, bridges. The core application of PALLADIOLibrary is Andrea Palladio - 3D geodatabase a complete 3D web geo-database grounded on GoogleEarth (Jones, 2007) where 3D models support a complex IS including:

1. 3D digital models representing as-built, and as metaphor of the observed objects, allowing a direct and semantic knowledge of the data;

2. 2D textual and iconographic materials approved and critically analysed by by CISAAP scientific Committee, composed of most qualified Palladio experts;

3. development of a new web-based architecture that allows multi-user customized access on different platforms, using standard guidelines.

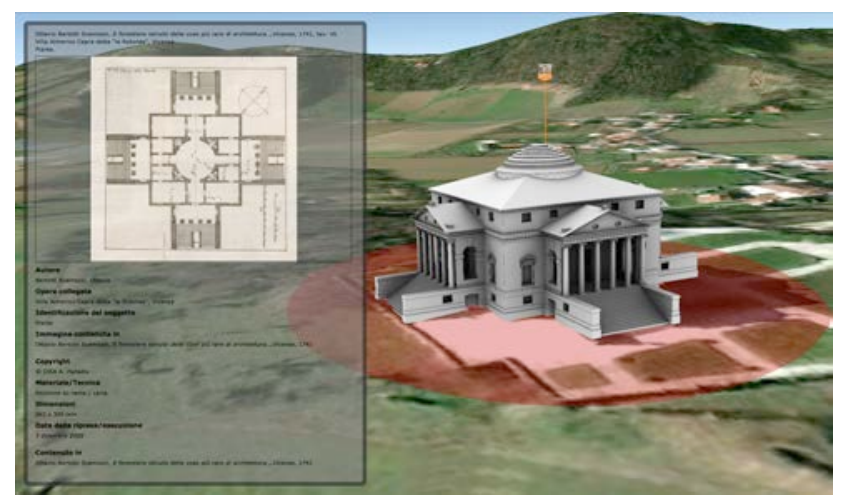

Figure 1. Andrea Palladio - 3D Geodatabase: interface with descriptive card of a historic treaty

The application was conceived as the preferred interface for accessing the Palladian database, to give access easily and userfriendly to individual buildings and whole information system. Above all, Andrea Palladio - 3D geodatabase allows a complete representation of architecture whose complexity can hardly be approached and understood through textual or iconographic documents. From this point of view the application is an updated evolution of the 1998 CD-ROM Andrea Palladio - Le Ville, no longer usable due to technological obsolescence (Gaiani et al., 1998), a multimedia application that gathers in a systematic way, for the first time, all textual and graphical documentation of about 40 Palladian villas, making available spatial and temporal navigation between the data and SQL queries. The added value of the new $3 \mathrm{D}$ geodatabase - compared to raw data or text-based approach is given by the inclusion of the buildings in their environment, allowing to discover unknown relationships between the villas and the environment, to evaluate their architectural occupancy and to quickly access a complex system of information collected by several extensive studies along the years. 
The application has been designed for different types of users: tourists, architecture historians, architects, curators charged of restoration, conservation and maintenance, and moreover managers and their staff; these are the reasons why a largely scalable interface, able to support different output devices and to work at different levels of iconicity, has been developed.

The system is open to future information additions and further applications, allowing all scholars to freely and easily add content without rewriting the source software or go through a webmaster, thus fostering rapid progress in research.

The more complex issue in the development of $3 \mathrm{D}$ geodatabase is the construction of the $3 \mathrm{D}$ models, core of the representation and description of Palladio works and the development of a model repository able to store and manage $3 \mathrm{D}$ assets.

In this paper we present the process developed for construction, management and visualization of the 3D models and the repository design features. There were made 51 high resolution 3D models giving back an extensive Palladian landscape. This is not an exhaustive set of 3D models, nor a static structure, but a network continuously updated with the advancement of studies. For this reason, we defined and used a series of standards and guidelines that enable new additions of 3D models to the system from the scientific community, keeping a substantial homogeneity of representation and data quality. Main topics addressed in the work concerned:

1. Construction of high resolution models from lidar survey for real-time rendering in Google Earth without loss of metric accuracy;

2. Development of fast survey methods using 'all in one' instruments combining in a single phase of work on site, acquisition of lidar, photogrammetry, topographic and photographic data aimed at modeling of artifact;

3. Study and development of a clear and specific shape grammar, starting from the Andrea Palladio treatise $I$ Quattro libri dell'architettura (1570), to achieve similarity and homology between Palladian architectures and their 3D digital representation.

\section{THE MODELS: GENERAL AND THEIR SOURCES}

3D models today available on Google Earth (such as the recent reproductions of Venice and Vicenza) aim to provide a complete view of urban volumes rather than illustrate each building faithfully and accurately. Most of the reconstruction, in fact, is not really obtained through geometric fidelity but rather through the use of textures, which are gained from aerial images. Instead the aim of our application is aimed to represent architectural shapes at the architectural scale starting from accurate 3D data capture. A second goal of our work was to create 3D models not merely replica of the original construction, but that would provide a semantic reading both of built artifacts and Palladio's design intentions, as Palladio treatise drawings and William Mitchell researches started in the years 1970 (Stiny \& Mitchell, (1978). Summarizing we could state that the aim of $3 \mathrm{D}$ models construction is essentially to improve the knowledge of Palladian architecture and to allow new insights to the scholars. At the same time these models will allow an easier understanding to citizens.

From a technical point of view main requirement of our 3D models will be to be ready to be included in the Palladian geodatabase, as territorial markers and as a visual description of that building. A final goal was to have 3D models with common features, in order to establish an extended 3D based IS, which can be used to do comparisons. As pointed out from many authors, this is not an easy task because the application have to ensure consistency, reusability and preservation of data. 3D models repositories development implies the knowledge of not only the raw data, but also the way in which they have been processed and completed. Because of the complexity of digitization's requirements, that emerges from the objects themselves, there is a plethora of methods and technologies which allows to build 3D models, even if rarely commensurable in procedures and outcomes, and this makes archiving process complex and fragmented in the results.

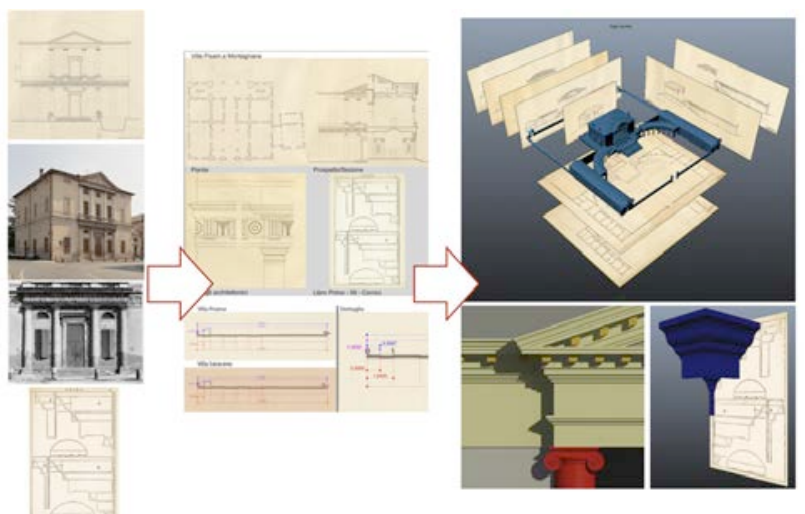

Figure 2. 3D modeling from 2D documentation.

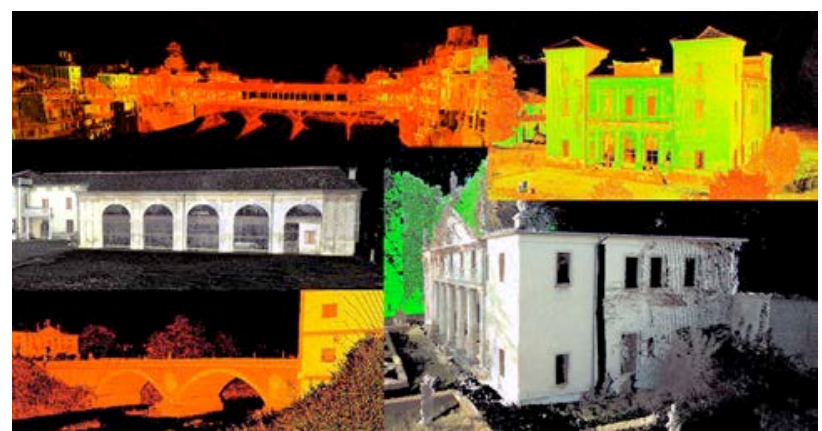

Figure 3. Laser scanner data capture.
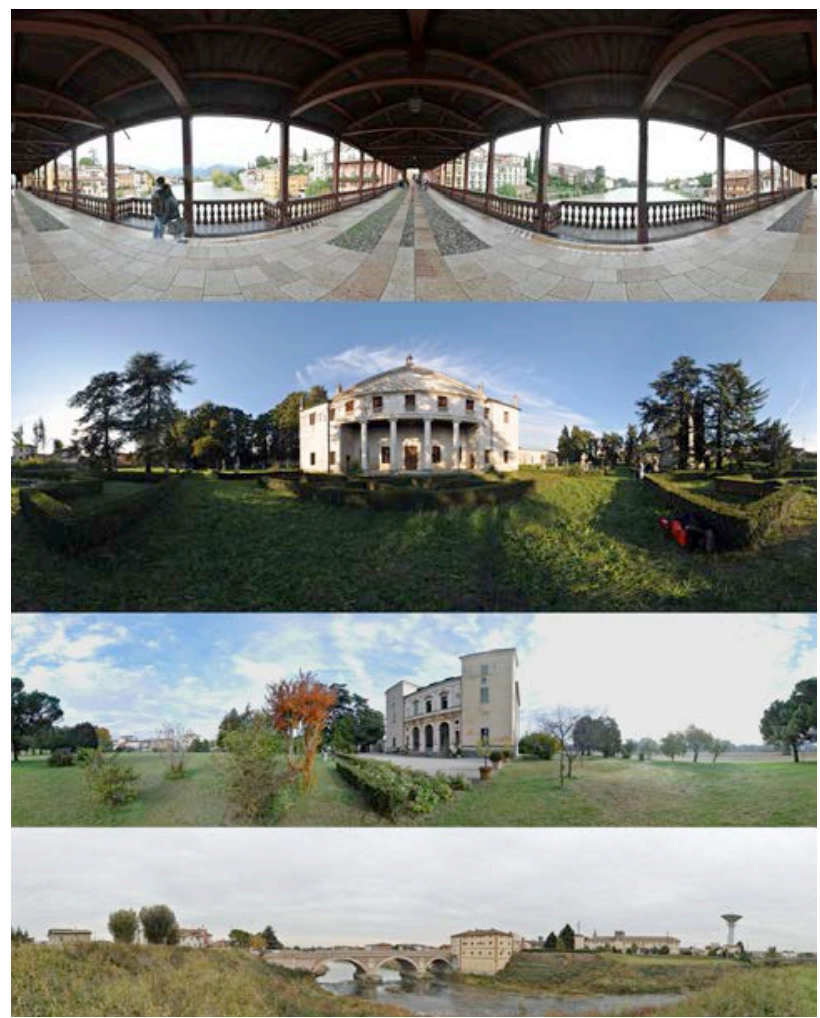

Figure 4. Spherical panoramas data capture. 


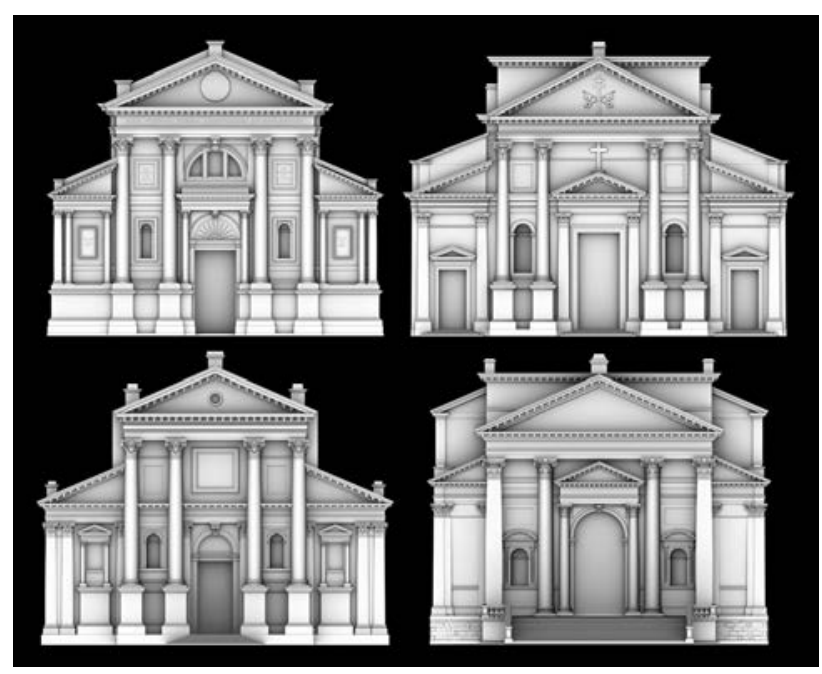

Figure 5. 3D models of the Palladian churches in Venice: Ambient Occlusion (AO) visualization.

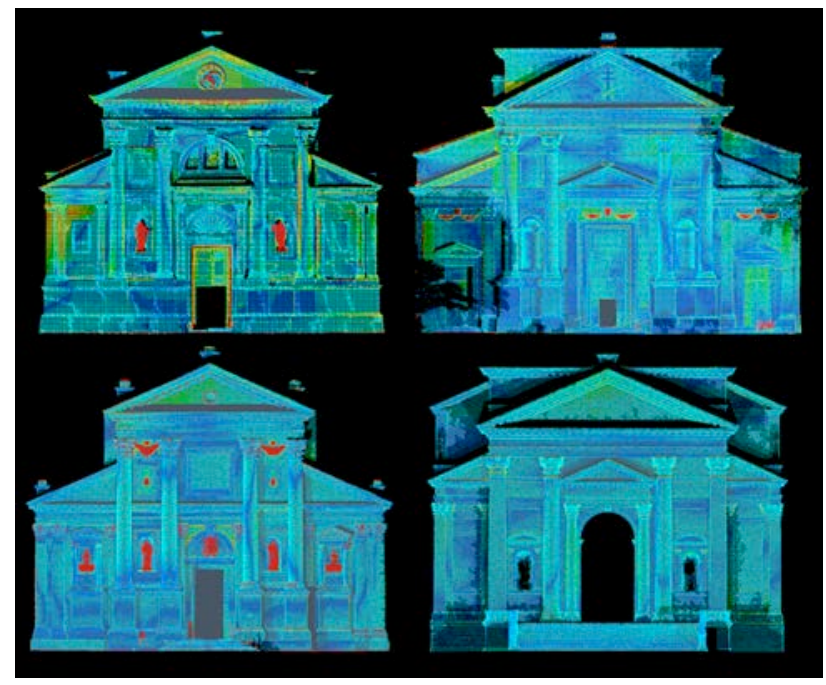

Figure 6. The Palladian churches in Venice: false color comparison between data acquired and the model for GE.

Our pipeline and repository overcome this problem with a specific solution, easy to understand and to be used by different modelers. The evolved methodology is based on three mutually linked aspects (modeling, subdivision into literally defined and/or constructed parts and visualization) that allow for the reproduction of high-definition $3 \mathrm{D}$ digital models, the classification of models and the allocation of additional information to each architectural element, besides the geometrical-dimensional details.

The aim was to enable the integration of different types of information collected by different operators and researchers at different places and times. These requirements lead to:

the use of widely accepted standards,

the definition of the quality of the information according to the level of detail of the visualization,

the continuous control of the data correspondence with the accuracies required.

3D models could be obtained from multiple and sometime integrated sources and technologies: 2D drawing plot of manual survey, photogrammetry, laser scanner.

To cope with this complexity and overcome this initial fragmentation, it was carried out a project involving four universities in which there were research groups with specific skills in the construction of three-dimensional models of architecture conceived as artifacts of communication and information systems: the University of Bologna, which also defined the modeling construction guideline, the IUAV University of Venice, which has made 3D models from laser scanning measurements of the four Palladian churches in Venice, the Polytechnic University of Marche which made models from 'all in one' instruments integrating lidar, photogrammetric and topographic data, and finally the University of Chieti-Pescara, who built most of the models based on existing surveys.

The digitalization of different materials concerning the Palladian work, made by CISAAP between 2001 and 2003 (the Digital Palladio project), allowed remote collaborative working using cloud computing technologies. This has reduced operational time and costs while improving the overall quality of the models through interactive sessions and review of collaborative working.

Many of the fifty one 3D models were constructed using the socalled Corpus dei rilievi delle fabbriche palladiane drawn up in the $70 \mathrm{~s}$ by Andrei and Ewa Soltan and Mario Zocconi. Drawings consist of a set of tables at different scales depending on the type of representation and detail $(1: 100-1: 10)$, which give an approximation from 1.5 to $3.5 \mathrm{~cm}$ depending on the original scale and digital reproductions and scans. Drawings in 1:25, 1:20 and sometimes 1:10 scales concern the architectural layout of the doors, windows and walkways. Both meters and Vicentine feet were used as units of measurement for the dimensioning. Deformations in drawings due to time, suboptimal conservation and scan conversion were corrected thanks to the presence of the graphical scale.

The 3D models of the Venetian churches (San Francesco della Vigna, San Pietro di Castello, San Giorgio Maggiore and Redentore) were made from an accurate and consistent database: the surveys made within the project carried out by the IUAV in 2008 for the Fifth Centenary of the birth of Andrea Palladio, with the aim of the study of the façades of the four Palladian churches of Venice (Borgherini et al., 2010).

The photogrammetric survey of the churches, lead by the IUAV photogrammetry lab, has been achieved using several instruments: Wild P31 metric camera, Rollei Metric 6006 and 6008 Phase One with 45mm, Nikon D3x with calibrated optics cameras, Riegl LMS-Z3DOi laser scanner. It was obtained a geometric model for every church, consisting of approximately 10 million points. From these points cloud was then obtained a photogrammetric plot at a nominal scale of 1:50 used as a foundation of the current work.

The 3D models of Villa Valmarana in Vigardolo, Villa Trissino in Meledo, the wing of Villa Thiene in Cicogna, the bridge on the Tesina in Torre di Quartesolo and the Ponte Vecchio in Bassano, are also the result of survey carried through a new method based on 'speed survey' using 'all in one' instruments, and the integration of photogrammetric and laser scanning data. The technique is a type of morphological survey, based on spherical panoramas data capture method developed in 2008 and firstly experimented in the case study of Villa Poiana in Poiana Maggiore (Clini, 2008) (Fangi, 2007).

In the case of PALLADIOLibrary we revamped the 2008 techniques with a new process able to guarantee metric accuracy, chromatic quality, versatility and speed in the acquisition, processing and output generation phases. Mainly the times of acquisition and data processing have been extremely reduced. Additionally, the representation and modeling processes are integrated in a single process with high saving of time and money. The whole process is based on a Leica $\mathrm{C} 10$ laser scanner that integrate all data acquisition phases into a single pass that allows us to capture a wide range of data: Lidar, Photography/Panoramic Photogrammetry, Topography. 
Among them, the most valuable outputs, in our case of study are those obtained from the integration of $3 \mathrm{D}$ point cloud and a photos data set where the images are perfectly aligned between themselves. Using the images acquired from the Leica C10's integrated camera and manual management of stitching process were produced spherical panoramas with a resolution 5 times higher than that one produced by the automatisms of the instrument (maximum resolution 41580 x 20790 pixels). In other words, our techniques allowed us to obtain an integrated information with typical accuracy of monoscopic photogrammetric systems, i.e. that is to say, between $1 / 1000$ to $1 / 500$ of camera-to-object distance.

\section{3D MODELS CONTRUCTION AND SEMANTICS}

The 3D model construction process of each building has been made with the maximum geometrical accuracy. Later, starting from the 3D model built with the maximum accuracy, we match the complexity of the model with the typical limitations of GE (i.e. number of polygons of each 3D architectural element, generating new 3D models at different Levels of Detail.

The 3D modeling system we defined is based on the accepted and general assumption whereby structures are described as a series of structured objects using a specific architectural lexicon. In this direction, our system aims to construct the model as a knowledge system analogous to the true building, using the same rules described by Andrea Palladio in his treatise I quattro libri dell'Architettura. It allows an immediate similarity and homology between the buildings and their architectural 3D digital representation.

Our method is described basically in Apollonio et al. (2010) and deals with the scheme developed by Larry Sass (2007).

In the Sass method the rules for a shape grammar demonstrate the need for additional information and illustration for rule building.

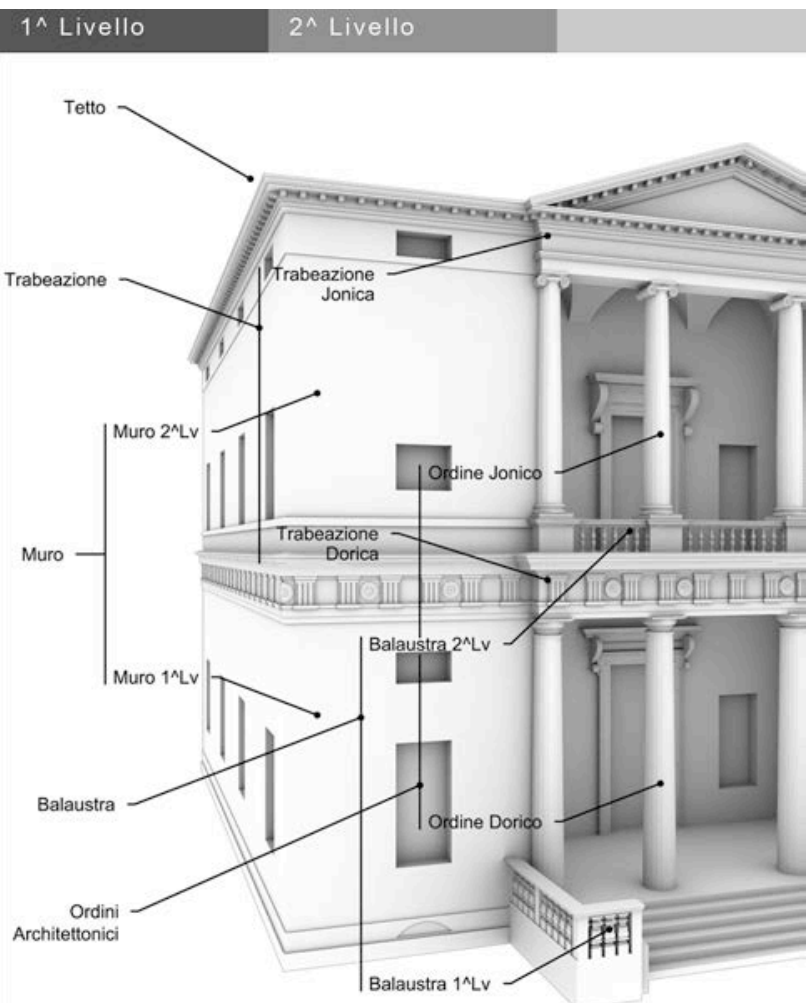

Figure 7. Villa Pisani a Montagnana: semantic structure of the $3 \mathrm{D}$ model; 1 st and 2 nd level.

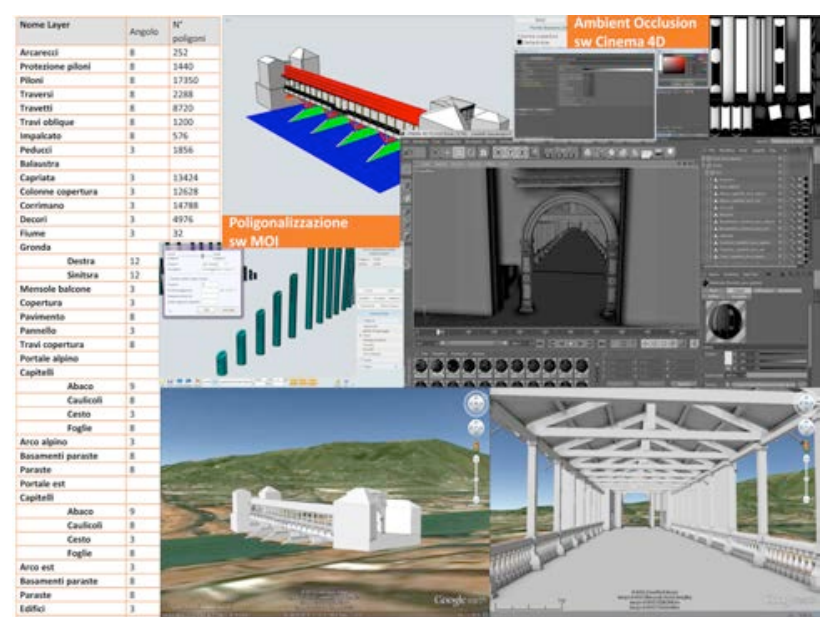

Figure 8. The Bassano bridge 3D semantic model construction: from acquired data to with $\mathrm{AO}$ visualization in GE.

However, if the Sass method is referred to the ideal project, we refer to the real built object, identifying, highlighting and discussing not only the scheme but also the constructive rules. Further developments allowed to integrate De Luca observations (De Luca, 2011) that aims to identify the potential of structuring heterogeneous information within semantically enriched 3D models of heritage buildings according to multiple contexts: the documentation of the state of conservation, the indexation and retrieval of iconographic sources, the analysis and representation of spatiotemporal changes. Finally we focused on the quality assessment procedures to ensure consistency and reliability of data throughout the whole $3 \mathrm{D}$ models acquisition and pipeline creation, as well as on the particular semantic reality-based structure adopted (Apollonio et al., 2012). We developed in this way methods to put an information system into a knowledge one, that we used for the 3D models of our 3D geodatabase. The tree-structure which leads the modeling of the Palladian buildings is defined starting from the applied 'shape grammars'. This is a flexible structure that could be organized over many hierarchical levels, allowing to handle the 3D models without loss of information according to a hierarchically related system of subsets, even in later stages of editing.

Our 3D models construction following semantic organization criteria, allowed keeping a well stated structure even after the stages of polygonization and translation of the original file into the output file formats, this way obtaining semantic models that can be used in a cognitive system. In addition, our model organization allows to manage the $3 \mathrm{D}$ models as multiresolution models and to subdivide them in consistent and hierarchically related subsets of a defined number of triangles/polygons in order to be included and visualized in GE. Finally our semantic pipeline allows to easily manage and integrate the metadata connected to the $3 \mathrm{D}$ model, to see and represent the data concerning uncertainty of the reconstruction, to value the guaranteed level of accuracy/precision, to verify the different 3D model versions, and, finally, to facilitate the comparative analysis between elements or wholes of architectural works. Each working group used one semantic model construction working with their preferred modeling software. The models had thus been created using different software for 3D modeling (i.e. Autodesk Maya \& 3DSMax, Cinema4D, Rhinoceros, MOI) and BIM systems (Autodesk Revit). Just at the end of the process they were optimized for the RTR visualization and translated in KMZ file format, which is a zipped archive file supported by Google Earth. 

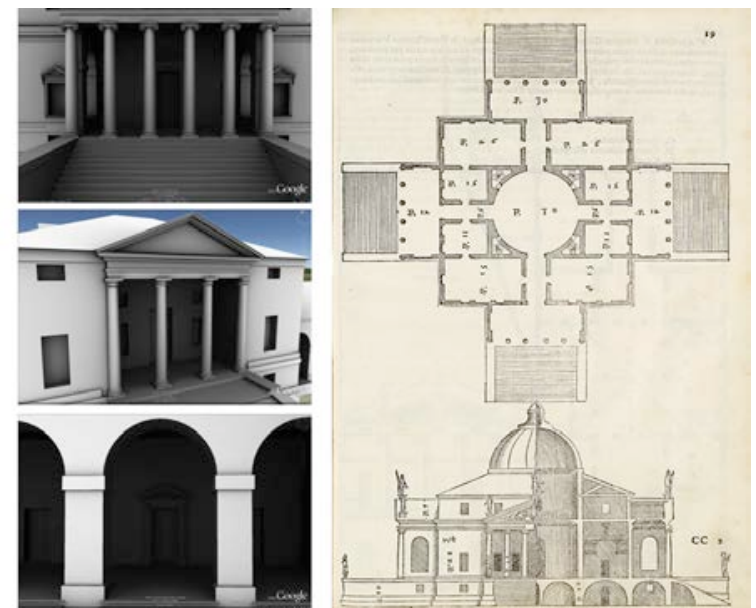

Figure 9. 2D to 3D visualization: from plates to GE

The KMZ file contains a set of characteristics that define the model (placemarks, images, polygons, 3D models, textual descriptions, etc..) and allows its placement on the 3D model of the Earth.

The content of a KMZ file, defined for the PALLADIOLibrary, is a single root KML document (notionally 'doc.kml') and a series of referenced files (DAE, TIF or PNG) in the subdirectory 'models' referenced in the KML, including networklinked KML files. DAE files describe geometry; while TIF or PNG files include mapping information of the corresponding DAE files. Each model was placed using the 3D geographic longitude, latitude and altitude, used by KML for its reference system, according to the internal coordinate system of GE based on the World Geodetic System of 1984 (WGS84) datum.

Summarizing, our 3D models construction pipeline consists of six steps: (Apollonio et al., 2011):

artifacts/buildings shape and color acquisition;

3D models construction;

models triangulation;

- Ambient Occlusion mapping;

- KMZ file production;

3D KMZ models placement in Google Earth.

In our pipeline in the case of 3D models constructed from point cloud, the main problem was not so much in shaping frames, capitals, columns and volutes (led at this stage mainly by the photogrammetric plot, beyond the points measured), but rather the need to build a regularized ideal model fitted on measured data. In other words, in the built models, capitals, columns, bases of the various orders are all identical to one another, just as the cornices have the exact same profile, the dentils at equal pitch, matching intercolumns and so on. This was obtained trying to minimize the differences between the ideal model, smooth and well-ordered, and the reality-based model, obtained from laser scanner and photogrammetric plot which show not only the measurement uncertainty but also the true life of the building with all the construction errors, structural failure and decay over the centuries. In our 3D models creation was therefore pursued the original design intentions keeping, free from building inaccuracies, subsidence and damages subsequent to the artifact construction.

The final visual appearance of our 3D models was conceived as strictly linked to the Palladian graphics. We conceived a reinterpretation of the contour techniques employed for the engraved plates of its treatise and used by itself in his design process able to display the shift from $2 \mathrm{D}$ drawings to $3 \mathrm{D}$ visualization. Accordingly was sought a type of visualisation/abstract representation, able to make clearly comprehensible the organization of architectural elements of
Palladio's buildings, and at same time able to overcome the limits of visualization quality of Google Earth's 3D models, where a simple Gouraud shading is implemented, which renders a three-dimensional visualization very flat. Having, finally, as an intrinsic condition the three-dimensional system already exposed, pushed towards a technique that can cope with both a 2D schema as well as reflecting the Palladian adumbratio which, ultimately, were the only ingredients capable of allowing an interpretation of his spatial graphic system.

This is why it was decided to apply the technique of Ambient Occlusion (AO) shading models introduced by Landis (Landis, 2002) and Bredow (Bredow, 2002) at SIGGRAPH 2002 used to achieve an effect of Global Illumination.

Quality control of 3D models constructed and its consistency were obtained realizing a shared repository that helps to collect and record the $3 \mathrm{D}$ models, verifying both the fidelity with accurate pre-defined quality metric standards and the responsiveness with the cataloguing and technical specifications of the GE based system. Built using a well-established structure already used in other cases (Baldissini et al., 2009) through its robust organization our system allows:

- data entry by different cataloguers;

- qualification of 3D models respect to the their LODs;

- quality check of data against the provided technical specifications;

- high resolution real-time visualization of models and their visual location on Google Maps;

- geo-referencing of 3D models according the Andrea Palladio 3D geo-referencing system;

- direct input into the whole 3D GIS.

The system manages data entry and visualization using the same interface.
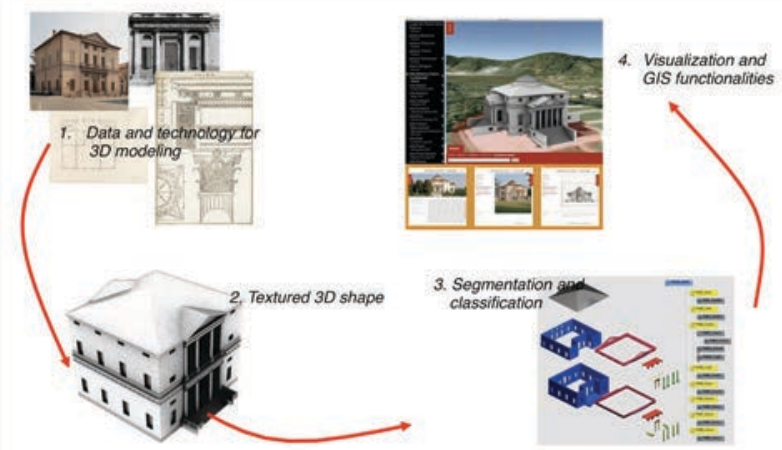

Figure 10. 3D model construction workflow
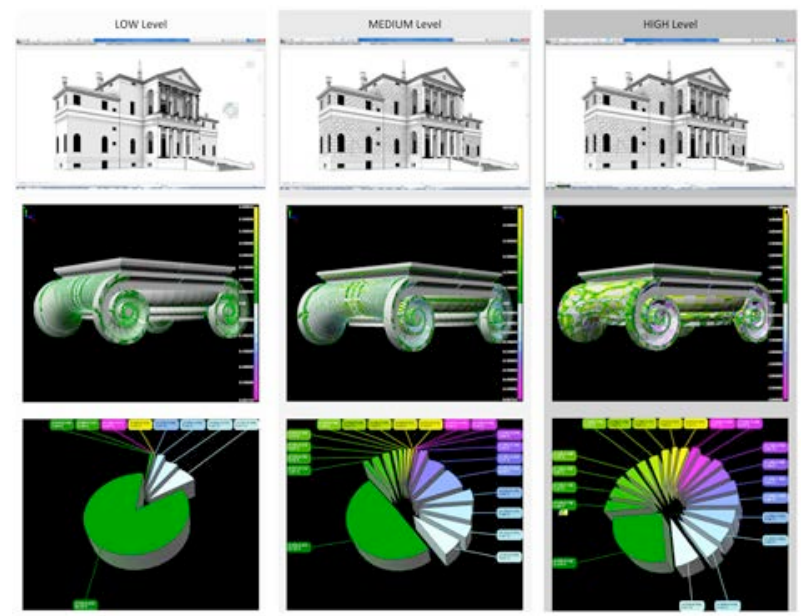

Figure 11. Villa Cornaro: 3D models at different levels of detail 
During data entry, the system can automatically provide the organization of files storing them in the final pre-defined folders.

Each artefact element is linked to a data sheet that contains an image that represents it. This organization leads to an immediate preview of the final display and therefore facilitates data entry.
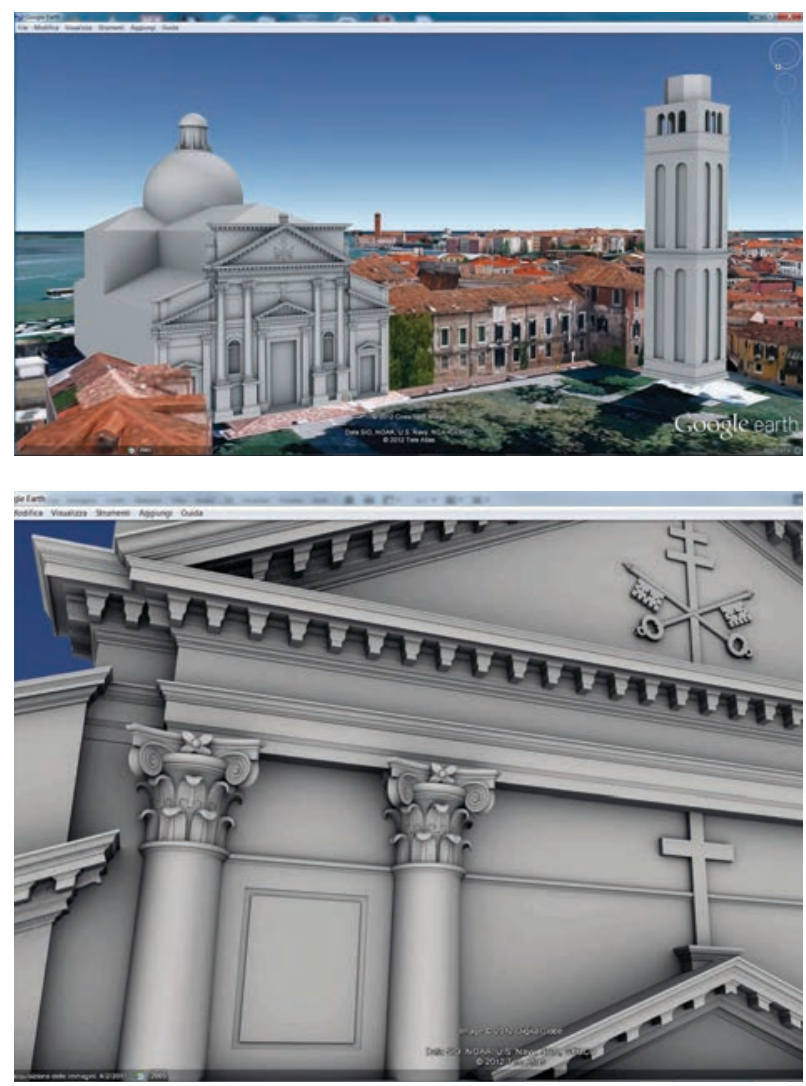

Figure 12. The church of San Pietro di Castello in GE.

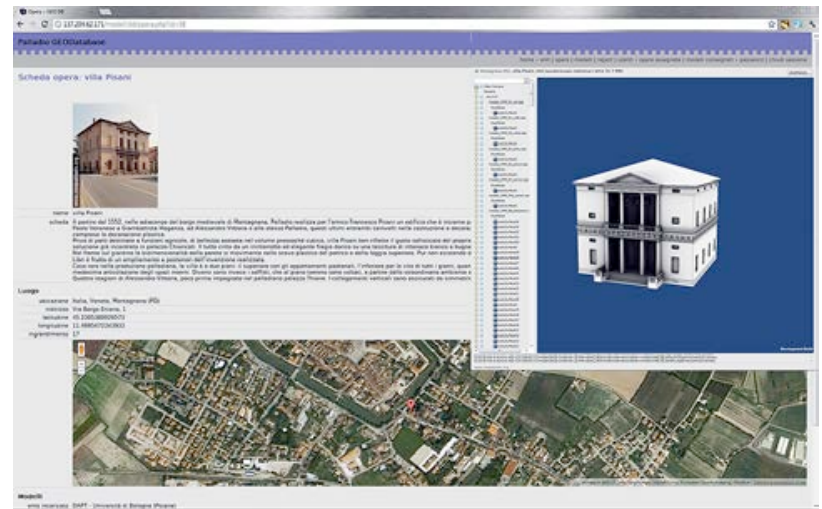

Figure 13.3D models repository interface

\section{REFERENCES}

Apollonio, F.I. et al., 2010. An Integrated 3D Geodatabase for Palladio's Work. International Journal of Architectural Computing, 8, 2, pp. 107-129.

Apollonio, F.I. et al., 2011. Construction, Management and Visualization of 3D Models for Cultural Heritage GIS Systems. Digital Media and its Application in Cultural Heritage, CSAAR Press, AMMAN, pp. 283-299.

Apollonio, F.I. et al., 2012. 3D reality-based artefact models for the management of archaeological sites using 3D GIS: a framework starting from the case study of the Pompeii Archaeological area. Journal of Archaeological Science, 39, pp. 1271-1287.

Baldissini, S., et al., 2009. An information system for the integration, management and visualization of 3D reality based archaeological models from different operators, ISPRS International Archive, XXXVIII-5/W1, pp. 1-8.

Beltramini, G., 2002. The Multimedia CD-ROMs of the CISAP: A resource for the study of architectural history and for the scientific examination and promotion of the works of Palladio. VSMM 2002 proceedings, Kiwisoft, Seoul, pp. 791-799.

Beltramini, G., Gaiani, M., (eds) 2003. Una metodologia per l'acquisizione e la restituzione dei giacimenti documentali dell'architettura. I materiali per lo studio di Andrea Palladio. POLI.design, Milano.

Borgherini, M.M. et al., 2010. Architettura delle facciate: le chiese di Palladio a Venezia. Nuovi rilievi, storia, materiali, Marsilio, Venezia.

Bredow, R., 2002. RenderMan on Film. SIGGRAPH 2002 Course 16 notes, RenderMan in Production.

Clini, P., 2008. Andrea Palladio. Per un catalogo critico dei rilievi. Storia e prospettive. In Palladio 1508-2008 - Il simposio del cinque centenario, Marsilio, Vicenza, pp. 405-412.

De Luca, L., 2011. Methods, formalisms and tools for the semantic-based surveying and representation of architectural heritage. Applied Geomatics, December.

Fangi, G., 2007. The Multi-image spherical Panoramas as a tool for Architectural Survey. ISPRS International Archive, XXXVI5/C53, pp. 311-316.

Gaiani, M., Beltramini, G., Burns, H., 1998. Andrea Palladio Le ville. CISAAP, Vicenza.

Gaiani, M., 2008. Modelli di Palladio - modelli palladiani. In Palladio 1508-2008 - Il simposio del cinquecentenario. Marsilio, Venezia, pp. 396-400.

Gaiani, M., Beltramini, G. (eds). 2012. Palladio Lab architetture palladiane indagate con tecnologie digitali. CISAAP, Vicenza, pp. 9-17.

Heitz Landis, 2002. Production-Ready Global Illumination. In SIGGRAPH 2002 Course 16 notes, RenderMan in Production.

Jones, M.T., 2007. Google's Geospatial Organizing Principle. Computer Graphics and Applications, 27, 4, pp. 8-13.

Palladio A., 1570. I Quattro libri dell'architettura, Venezia.

Sass, L., 2007. A Palladian construction grammar - design reasoning with shape grammars and rapid prototyping. Environment and Planning B: Planning and Design, 34, pp. 87106.

Shan J., Toth, C.K., 2009. Topographic Laser Ranging and Scanning. Principles and Processing. CRC Press, London.

Stiny, G., Mitchell, W.J., 1978. The Palladian grammar. Environment and Planning B: Planning and Design, 5, 5-18. 